\title{
EFFECT OF WHOLE AND PARTIAL SUBSTITUTION OF RICE HUSK ASH FOR QUARTZ IN TRIAXIAL PORCELAIN COMPOSITE FABRICATION
}

\section{EZEOKE EMMANUEL KENECHI ${ }^{1}$, AJANAKU CHRISTIANA OLUWATOYIN ${ }^{1}$, ADEMOSUN THERESA OLABISI ${ }^{1}$, AJANAKU KOLAWOLE OLUSEYI ${ }^{*}$}

${ }^{I}$ Chemistry Department, College of Science \& Technology, Covenant University, Km. 10, Idiroko Road, Canaan Land, Ota, Ogun State, Nigeria

\section{ABSTRACT}

Rice husk ash (RHA) was wholly and partially substituted for quartz, in a triaxial porcelain mixture of kaolin, quartz, and feldspar in this study. The effect of this substitution on the physico-mechanical properties (bulk density, apparent porosity, linear shrinkage, and flexural strength) was studied at heating temperatures of $1200^{\circ} \mathrm{C}, 1300^{\circ} \mathrm{C}$ and $1400^{\circ} \mathrm{C}$. Investigation of the phase and microstructural evaluation was analysed using SEM/EDX and XRD, respectively. The sintered samples showed improved physico-mechanical properties as the temperature increases as expected of porcelain materials. There was no significant change in the bulk density; however, the partially substituted compositions (60 and 40\% RHA) displayed better flexural strength when compared to the wholly replaced sample and unreplaced sample. The presence of mullite and cristobalite in the sintered mix contributed to this development. The study, therefore, reveals that partial and controlled replacement of quartz, with $\mathrm{RHA}$ yield beneficial results.

KEYWORDS: Rice husk, quartz, porcelain, cristobalite, feldspar and kaolin

Received: Aug 18, 2020; Accepted: Sep 08, 2020; Published: Nov 10, 2020; Paper Id.: IJMPERDOCT202039

\section{INTRODUCTION}

Triaxial porcelain materials have been widely used of recent due to their chemical stability, high compressive strength, and excellent insulating properties (Sedghi et al., 2012; Sánchez et al., 2006; Oluseyi et al., 2013). The gradual depletion of naturally occurring raw materials for ceramic production coupled with the high cost of these materials has made seeking an alternative to natural source of paramount importance. Kaolin, quartz and feldspar in the ratio of 50:25:25 is the primary composition of triaxial porcelain composite. Each of these raw materials played their role in the physico-mechanical properties of the composite. The specific roles played by these raw materials have been widely studied (Haldar and Das, 2012; Carty and Senapati 1998). Kaolin is utilised for its flexibility, hence its ability to conform to the desired shape when treated. The quartz is responsible for the mechanical strength and rigidity, and this vital in attaining a solid body for the ceramic porcelain. The feldspar acts as a flux in the trio-combination; it helps in reducing the melting temperature of the porcelain. There are situations where one or two components have been replaced entirely or partially (Oluseyi et al., 2013; Firat et al., 2012). Some studies have carried out the use of abundantly available industrial waste as an alternative source for either quartz, feldspar, or clay in triaxial porcelain composition. Some of the replacement processes include the use of fired porcelain scrap to replace quartz (Rodríguez et al., 2019); quartzite waste was used in replacing feldspar (Medeiros et al., 2019); Soda-lime scrap glass as a replacement for feldspar (Oluseyi et al., 2013; Tucci et al., 2004); blast furnace and metallurgical slag replacing feldspar (Dana and Das, 2008; Dana and Das, 2003); Fly ash replacement for quartz (Dana et al., 2004; Dana et al., 
2005).

Rice is one of the most extensively consumed sources of food worldwide, which then makes rice husk (RH) as one of the most widely obtainable agricultural wastes in many rice-producing countries around the world. Studies have shown that rice paddy consists of about $20 \%$ rice husk with a total of 120 million tonnes annual production (Bondioli et al., 2007). Rice husk is usually burnt or dumped as waste in the majority of countries where rice is cultivated. The product formed from the burning of rice husk is known as rice husk ash (RHA). RHA is high in silica (>90\%), therefore making it an excellent cementitious material (Lim et al., 2018). Several authors have carried out the utilisation of RHA in ceramics materials; for an instant, Serra et al. (2016) carried out the synthesis of mullite ceramics through the solid-state sintering of RHA and alumina. Phase, microstructural studies and rietveld refinement show that RHA is beneficial as it offers close resemblance with silica. In another study, Kunchariyakun et al. (2015) studied the properties of autoclaved aerated concrete incorporating rice husk ash as a replacement for fine aggregate. The result from the study shows that substituting quartz for rice husk ash showed a reduction in autoclaving time due to high reactivity of silica in rice husk to hydration. In addition to reducing the environmental impact of rice husk waste and minimising the cost of producing porcelain materials, it is good to know that rice husk contains no hazardous chemical (Kumar et al., 2012).

In this present study, agricultural waste, RHA, is used as an alternative to quartz in the triaxial porcelain mixture in the production of whiteware ceramics. The effects of RHA utilisation was discussed in terms of physico-mechanical properties, phase identification and microstructural evaluation.

\section{MATERIALS AND METHODS}

\subsection{Materials}

Feldspar and quartz were obtained from Beta Glass Plc, Agbara Industrial Estate, Lagos State, Nigeria. The kaolin was obtained from Abule Onikosin road in Abeokuta, while the rice husk was collected and crushed at the Abeokuta rice milling firm. The rice husk was air-dried before ashing to ensure minimal moisture content.

\subsection{Experimental}

$210 \mathrm{~g}$ of rice husk was weighed into crucibles using Digital Mettler Toledo ML204T Analytical Balance. It was then subjected to calcination in a digitally controlled muffle furnace at $500{ }^{\circ} \mathrm{C}$ for two hours. It was allowed to cool for 24 hours before removing from the oven. The quartz was pulverised using a crushing machine; afterwards, it was sieved to achieve uniform particles. The feldspar already in fine form was also sieved in a 100 mesh B.S. size.

$500 \mathrm{~g}$ batching of the constituent materials was prepared, as shown in Table 1 as the composition of the test materials. $10 \%$ distilled water was added to each of the batches and was milled in a Simoloyer high energy ball milling machine for 3 hours, forming a homogenous slurry in the process. The preserved slurry was then dried in an oven for 24 hours after which was ground to its powdered form.

Table 1: Batch compositions of the samples

\begin{tabular}{|c|c|c|c|c|}
\hline Components & EK1 (g) & EK2 (g) & EK3 (g) & EK4 (g) \\
\hline Kaolin & 250 & 250 & 250 & 250 \\
\hline Quartz & 125 & Nil & 50 & 75 \\
\hline
\end{tabular}




\begin{tabular}{|l|l|l|l|l|}
\hline Feldspar & 125 & 125 & 125 & 125 \\
\hline
\end{tabular}

The resulting form was sieved through a mesh to ensure uniformity if sample particles, in preparation for the moulding. The dried masses were powdered and moistened with about $5 \%$ water to enhance the binding ability. The moistened powder was therefore uniaxially pressed in a rectangular mould of dimensions $65 \mathrm{~mm} \times 14 \mathrm{~mm} \times 5 \mathrm{~mm}$ at a pressure of $36 \mathrm{MPa}$ using a hydraulic press. The procedure was repeated for all subsequent batches. Enough bars were moulded and air-dried for 24 hours. In preparation for firing, the bars were oven-dried at $110^{\circ} \mathrm{C}$ for 24 hours, this was further to remove the presence of moisture in the bars. The bars were sintered at three temperatures of 1200,1300 and $1400{ }^{\circ} \mathrm{C}$ at a heating rate of $5{ }^{\circ} \mathrm{C} / \mathrm{min}$ for 3 hours. The sintered samples were then subjected to the following characterisation: percentage apparent porosity (\%AP); bulk density (B.D.), percentage linear shrinkage (\%LS) and Flexural strength. Bulk density and apparent porosity were derived using Archimede's principle. Linear shrinkage was obtained by calculating the difference in the length before and after sintering. The sintered samples flexural strength was analysed by INSTRON 5500R through three-point bending process. The microstructural and phase identification was determined via CuKa radiation X-ray diffractometer within the range of $10-80^{\circ}$ at $2 \theta$. The samples were further treated with SiC powder followed by diamond paste polish to enhance gold coating on its surface [Edwards, Scancoat]. FESEM was used to determine the morphology and the secondary electron image of the etched surface[Zeiss].

\section{RESULT AND DISCUSSIONS}

\subsection{Physico-Mechanical Properties of the Compacts}

The linear shrinkage, apparent porosity, bulk density, and flexural strength of the sintered test samples as it relates to firing temperature are shown in Fig. 1(a-d), respectively. As observed in Figure 1a, the percentage linear shrinkage increases with temperature for all the compositions except for EK1. Linear shrinkage in porcelain bodies is because of the sintering within and between the constituent materials and reaction during sintering (Haldar and Das, 2012; Jamo et al. 2015). As also observed in Figure 1a, the increase in shrinkage was a function of both temperature and gradual substitution of quartz with RHA. The linear shrinkage of the samples increased with RHA addition. The increase observed in the shrinkage of sample EK2 (total replacement) at $1400{ }^{\circ} \mathrm{C}$ in comparison with that of sample EK1 ( $0 \%$ RHA) was $0.6 \%$. Meanwhile, the increase observed for EK3 (60\% quartz replacement), and EK4 (40\% quartz replacement) was 0.5 and $0.4 \%$ respectively. Linear shrinkage is an essential parameter in determining the quality of porcelain. The reason for the high value of shrinkage observed in EK2 (complete quartz replacement) is a result of the soft nature of RHA and the presence of silica. This may unfavourably influence the samples upon vitrification. Higher shrinkage amount can lead to the formation of cracks and deformations. Researchers desire a lower value of shrinkage as it reduces the possibility of defects and deformation during production (Prasad et al., 2001; Correia et al., 2006).

As usually observed in porcelain bodies, the percentage apparent porosity reduces with increase in temperature across all the samples. As shown in Figure $1 \mathrm{~b}$ at $1400^{\circ} \mathrm{C}$, when full vitrification is attained, the least A.P. of $4 \%$ was observed for EK2 (total quartz replacement with RHA) while the highest \% A.P (13\%) was observed for EK4 (40\% quartz replacement with RHA). The decrease in porosity observed in the RHA substituted samples is attributed to the formation of the glassier phase in the microstructure due to the high amount of silica present in RHA. Figure 1c shows the bulk density of all the samples across the different sintering temperatures, from the figure it was observed that there is no much variation in the value of the bulk densities of the partially substituted samples, EK3 (1.8) and EK4 (1.9). However, the totally replaced model, 
EK2, has a higher bulk density when compared to the standard EK1. This may be because RHA has a higher density than quartz; therefore, total replacement of quartz with RHA will increase the density of sample EK2. Besides, the presence of RHA increases the liquid phase, and this enhances the densification process. The alkaline oxides present in RHA might have also contributed to the densification. Figure 1d shows the variation in the flexural strength (F.S.) of the samples. At full vitrification, the flexural strength of the samples increases with RHA addition but reduces marginally when the amount of RHA exceeds $60 \mathrm{wt} \%$. EK3 (60\% quartz replacement) exhibited the highest strength of $67 \mathrm{MPa}$. The increase in the flexural strength of EK3 was about 7\% higher than the standard composition EK1. Sample EK2, complete replacement of quartz has a flexural strength of $52 \mathrm{MPa}$, which is $16 \%$ lower than the control composition (EK1). The decrease in strength experiences with EK2 could be as a result of the increase in glassy phase in the microstructure, which could lead to cracking and deformation. The presence of feldspar acting as a flux may have contributed to the strength exhibited by EK3.

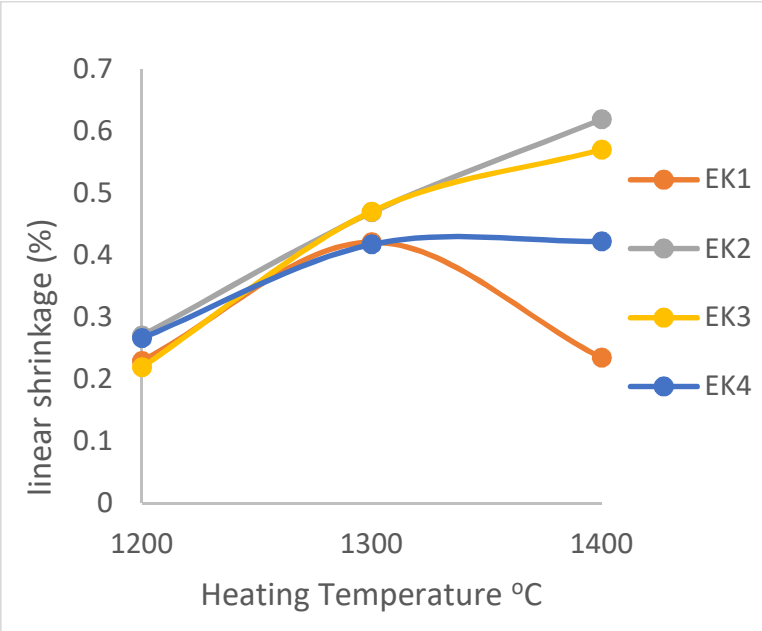

$\mathbf{a}$

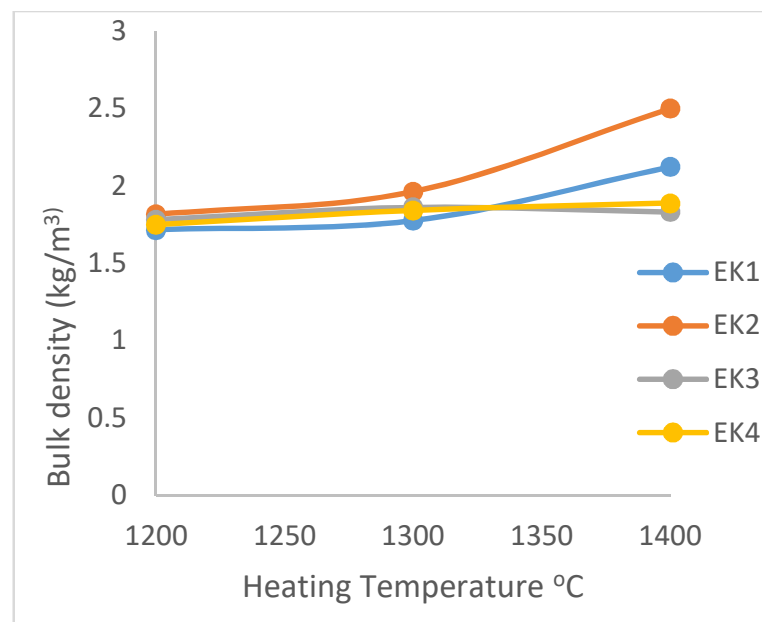

C

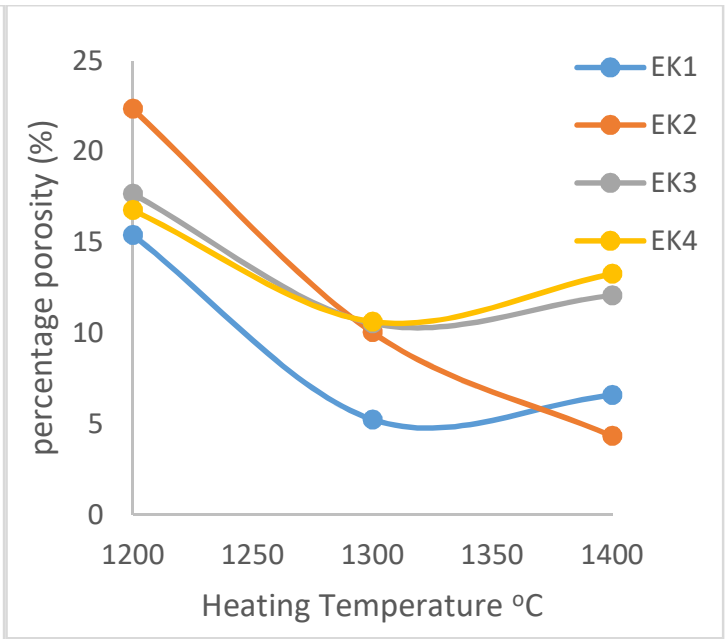

b

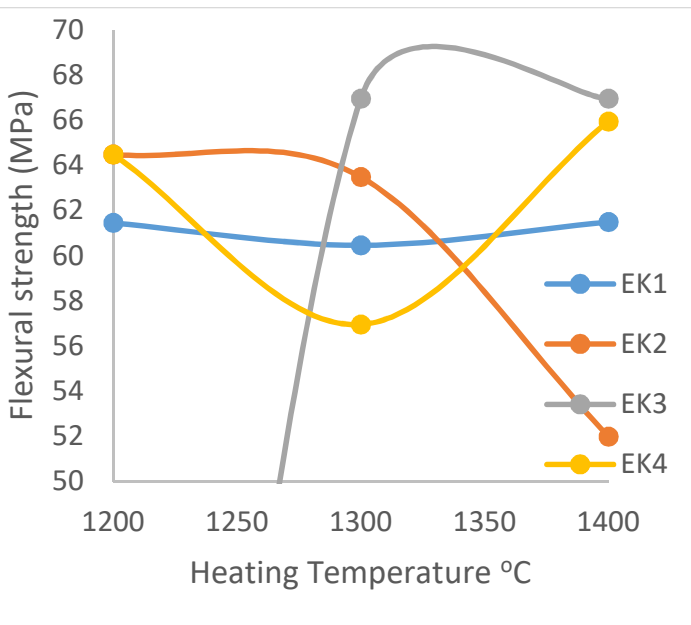

d

Figure 1: Variation in (a) linear shrinkage (b) \% apparent porosity (c) bulk density and (d) flexural strength of EK1, EK2, EK3 and EK4 samples with relation to sintering temperature. 


\subsection{Phase Identification and Microstructural Study}

The SEM micrograph of the samples at $1400^{\circ} \mathrm{C}$ are shown in Figures 2(a-d) for all the samples. SEM micrograph for EK1 showed the presence of free quartz and tangible structure of crystalline mullite. The presence of unreacted quartz in the microstructure may be the reason for the low flexural strength exhibited by the sample. A little amount of mullite and quartz was observed in the SEM micrograph of EK2. A closer look shows the presence of glassy phases made up of cristobalite and low quantity of quartz. This further explains the reason for the low flexural strength exhibited by EK2 as low amount of quartz and high amount of cristobalite is detrimental to strength in ceramic materials (Aladesuyi et al. 2017; Prasad et al., 2002). The micrographs of EK 3 and EK4 showed the presence of interlocked secondary mullite embedded in the glassy matrix. The improvement in the flexural strength observed in the wholly substituted samples may be due to the presence of acicular mullite with well-round edges and good aspect ratio observed in the microstructure. Also, the presence of pores and quartz relics are minimal in the micrograph.

XRD study was carried out on the sintered compacts to determine the crystalline phases formed during the sintering at $1400^{\circ} \mathrm{C}$ when vitrification has been maximised. The XRD patterns are presented in Figure $3 \mathrm{a}-\mathrm{d}$. The major crystalline phases observed from the XRD patterns are quartz and cristobalite while halloysite, microcline, mullite and sillimanite were minor peaks. There was no significant difference in the patterns, however, the length of the cristobalite peak was more intense in RHA substituted quartz (EK2, EK3 and EK4) which is due to the presence of high silica from RHA. The intensity of the peak of quartz at around 2 theta $27^{\circ}$ to reduce drastically for sample EK2 while it remains the same for the partially substituted samples (EK3 and EK4). This is an indication that the presence of RHA reduces the presence of free quartz; this also corroborated the reason for the low porosity exhibited when quartz was totally replaced (EK2). Minor phases of mullite peaks were more pronounced in EK3, and this may be the reason for the high strength observed in this sample.

It is, therefore, possible to reduce significantly to a large extent, the defects encountered in the microstructure of triaxial porcelains and also enhance the strength through the partial and controlled replacement of quartz with RHA.

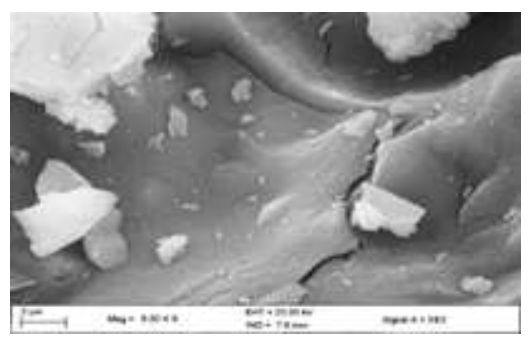

a

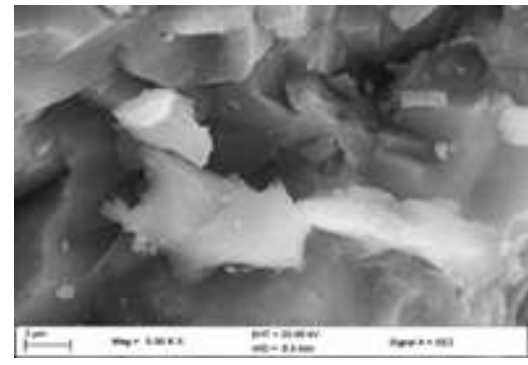

C

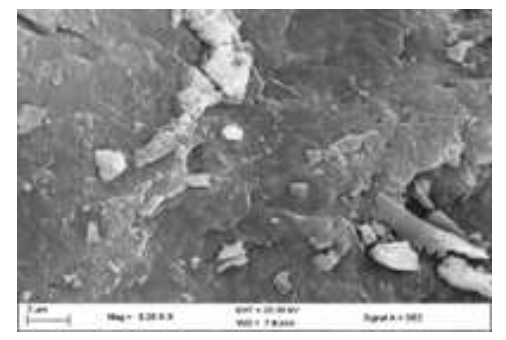

$\mathrm{b}$

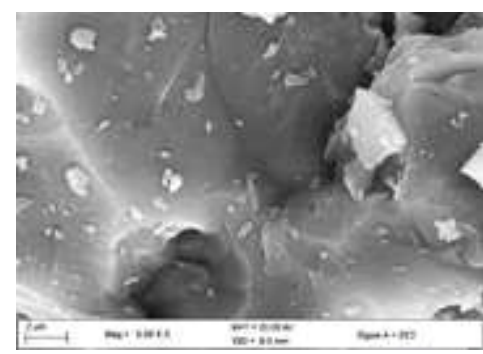

d

Figure 2: SEM micrographs of (a) EK1 (b) EK2 (c) EK3 and (d) EK4 samples sintered at $1400^{\circ} \mathrm{C}$ 


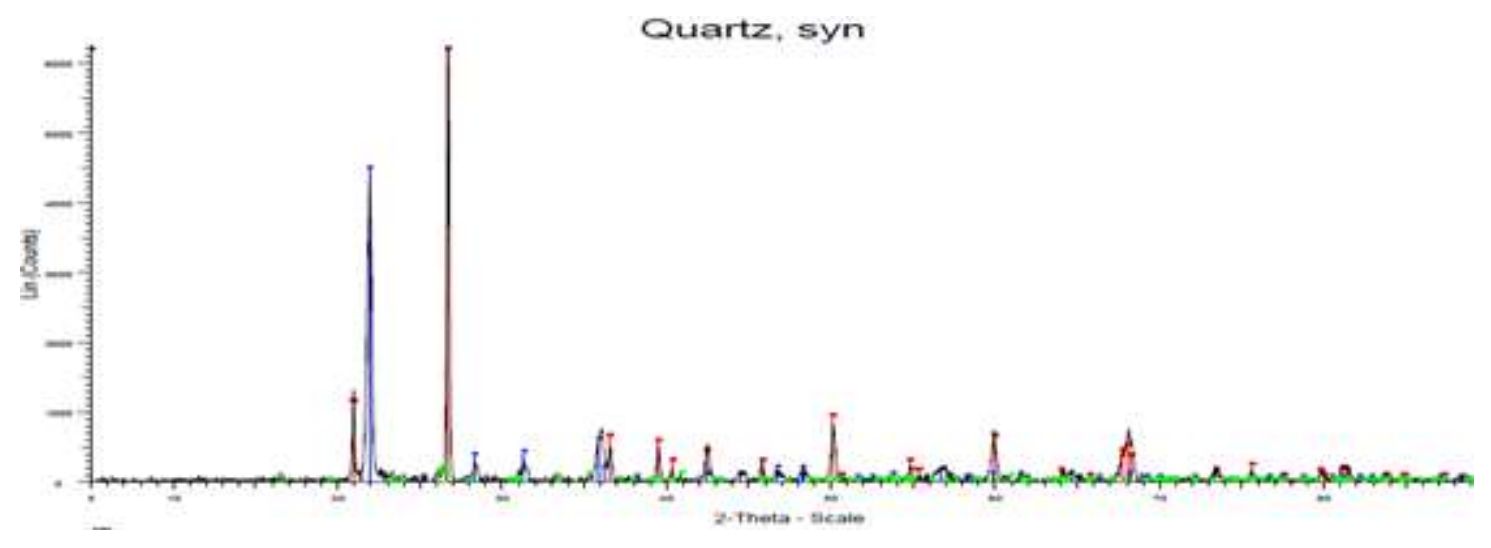

Figure 3 (a): XRD pattern of EK1 sample sintered at $1400^{\circ} \mathrm{C}$

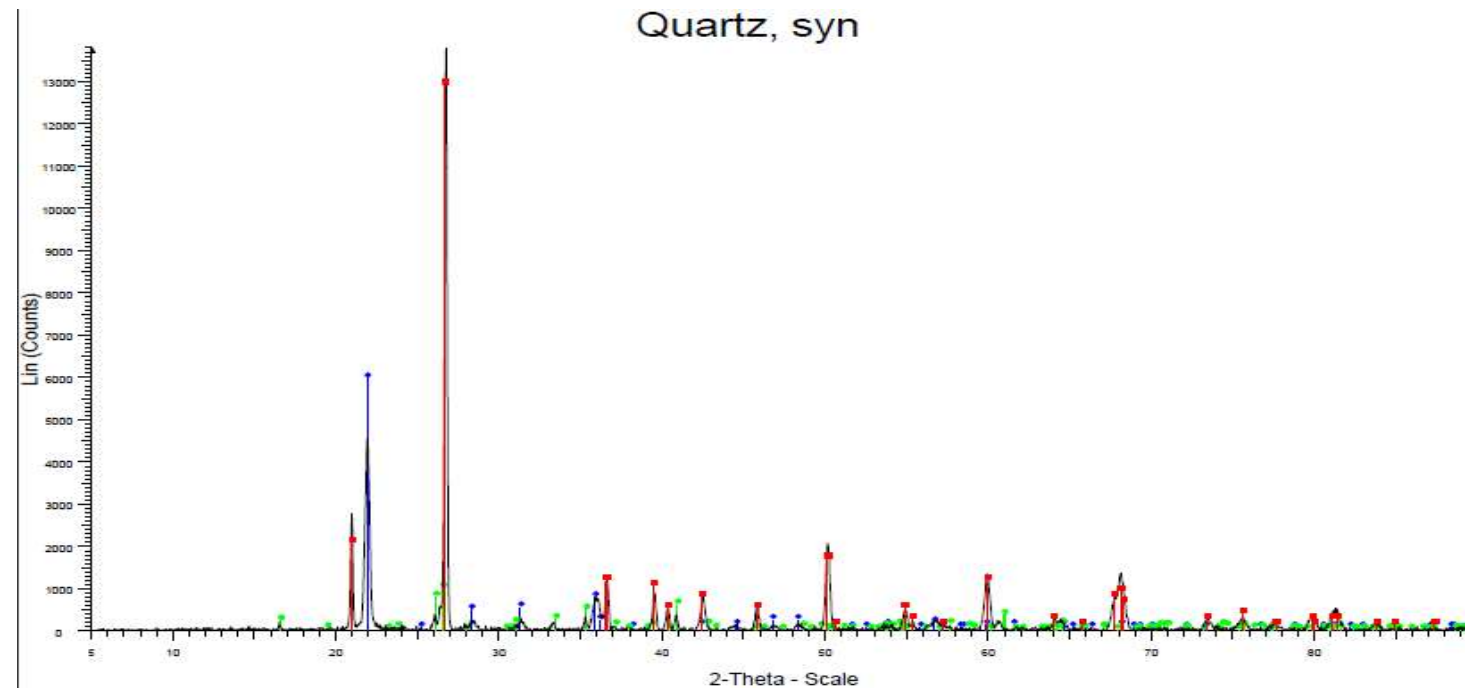

Figure 3 (b): XRD pattern of EK2 sample sintered at $1400^{\circ} \mathrm{C}$

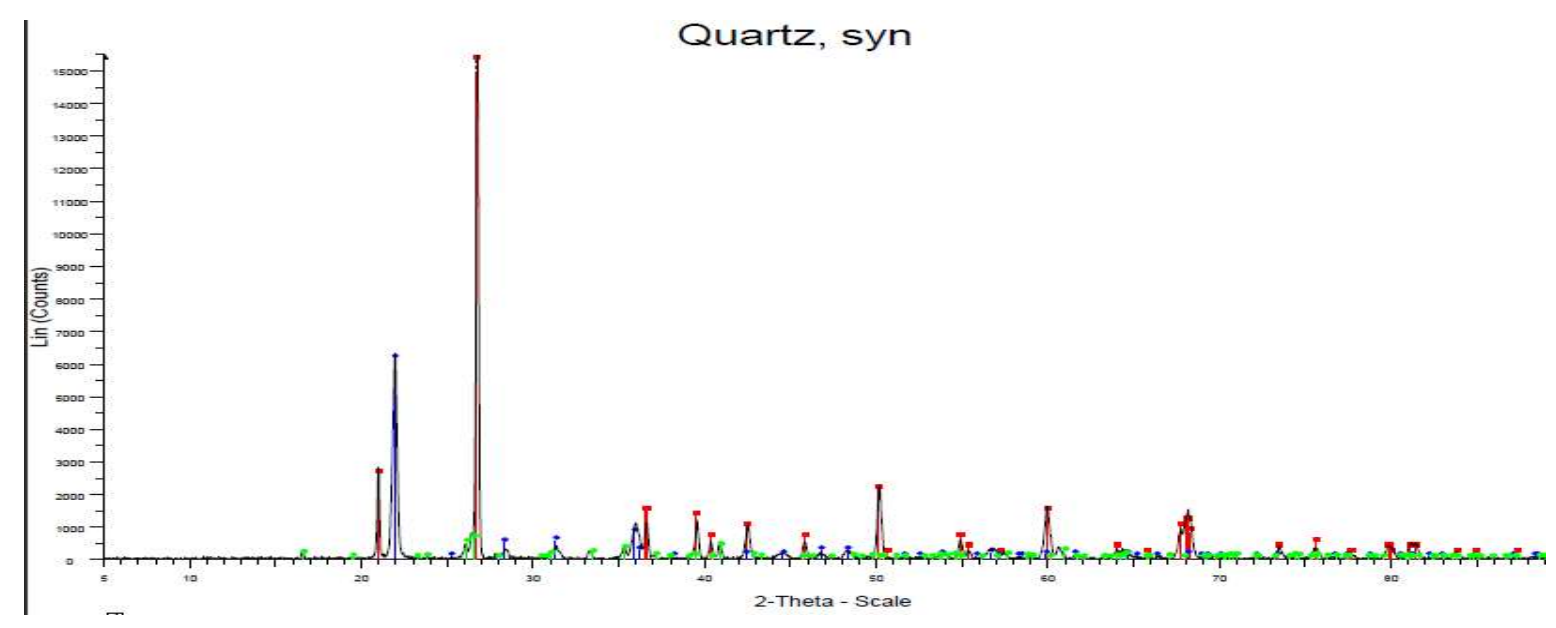

Figure 3 (c): XRD pattern of EK1 sample sintered at $1400^{\circ} \mathrm{C}$ 


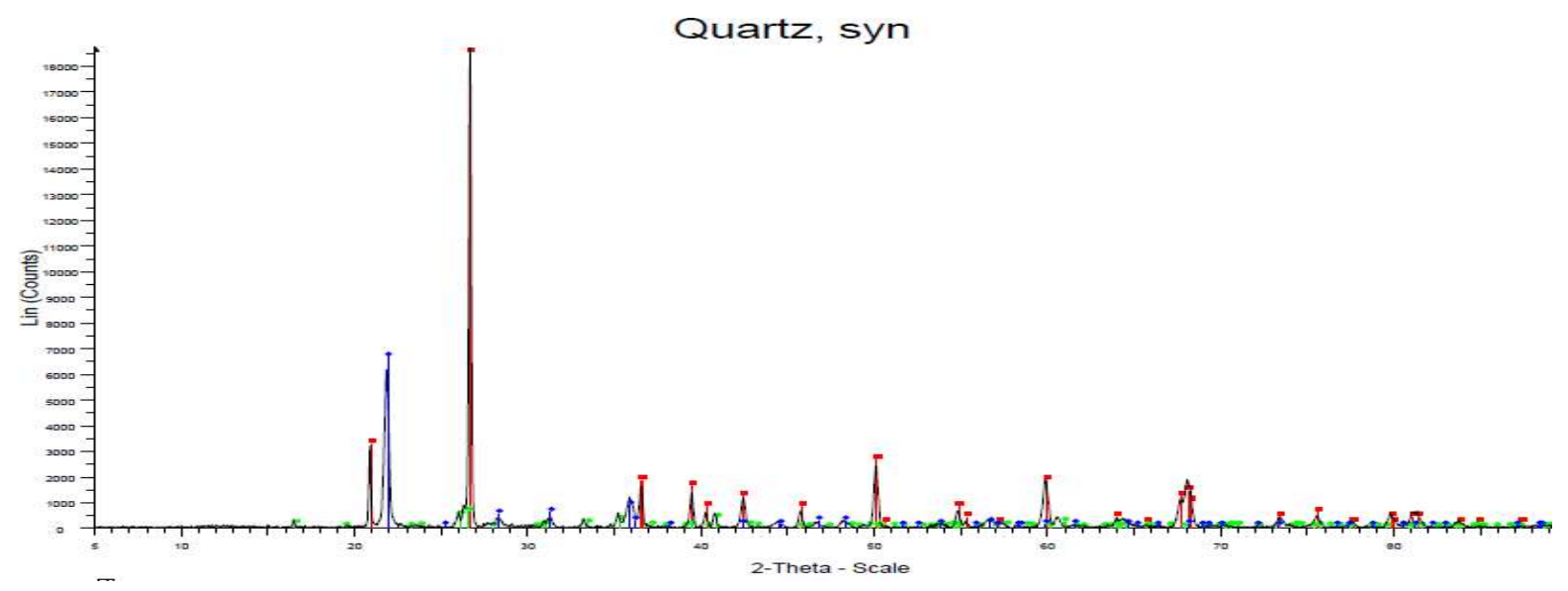

Figure 3 (d): XRD pattern of EK4 sample sintered at $1400^{\circ} \mathrm{C}$

\section{CONCLUSIONS}

The following conclusions were deduced from this study:

- Total replacement of quartz by RHA (EK1) yielded desirable bulk density and porosity; however, the flexural strength was low when compared to the other compositions. This can be explained based on the high amount of cristobalite and primary mullite as revealed by the XRD and SEM micrograph, respectively;

- Sample EK3 (60\% quartz replacement) and EK4 (40\% quartz replacement) exhibited good physico-mechanical properties, most especially at the vitrifying temperature. This can be ascribed to the presence of secondary mullite in a glassy matrix as revealed by the SEM micrograph;

- The study reveals that the mechanical properties of triaxial porcelains can be enhanced through the partial and controlled replacement of quartz with RHA in the composition; and

- The use of RHA in ceramic products will not only mitigate the menace of environmental pollution but will also contribute positively to the economical production of porcelains.

\section{ACKNOWLEDGEMENTS}

Authors are greatful to Covenant University for providing financial assistance to carried out this research work.

\section{REFERENCES}

1. Aladesuyi, O., Pal, M., Emetere, M.E., Das, S.K. \& Ajanaku, K.O. (2017). Influence of transition metal ion (Mn $\left.{ }^{4+}\right)$ on mullite formation in a mixture of 50:50 Nigerian kaolin and calcined alumina. Cogent Engineering. 4, 1396947 https://doi.org/10.1080/23311916.2017.1396947

2. Bondioli, F., Andreola, F., Barbieri, L., Manfredini, T. \& Ferrari, M.A. (2007). Effects of rice husk ash (RHA) in the synthesis of (Pr, $\mathrm{Zr}) \mathrm{SiO}_{4}$ ceramic pigment. Journal of the European Ceramic Society, 27, 3483 - 3488.

3. Carty, W.M., \& Senapati, U. (1998). Porcelain-raw material, processing, phase evolution, and mechanical behaviour. J. Am. Ceram. Soc., 81(1), $3-20$

4. Correia, S.L., Oliveira, A.P.N., Hotza, D., \& Segadães, A.M.. (2006). Properties of triaxial porcelain bodies: Interpretation of statistical modeling. Journal of the American Ceramic Society, 89(11), 3356 - 3365.

5. Dana, K. \& Das, S.K. (2008). Enhanced resistance to thermal cycling of slag-containing vitrified porcelain tiles. Industrial Ceramics, 28, $121-124$. 
6. Dana, K. \& Das, S.K. (2003). High strength ceramic floor tile compositions containing Indian metallurgical slags. J. Mater. Sci. Lett., 22, 387-389.

7. Dana, K., Das, S., \& Das, S.K. (2004). Effect of substitution of fly ash for quartz in triaxial kaolin-quartz-feldspar system. J. Eur. Ceram. Soc., 24, 3169-3175.

8. Dana, K., Dey, J., \& Das, S.K. (2005). Synergistic effect of fly ash and blast furnace slag on the mechanical strength of traditional porcelain tiles. Ceram. Int., 31, 147-152.

9. Firat, F.A., Ercenk, E., \& yllmaz ş. (2012). Effect of substitution of basalt for quartz in triaxial porcelain. Journal of Ceramic Processing Research, 13(6), 756-761.

10. Haldar, M.K. \& Das, K.S. (2012). Effect of substitution of sandstone dust for quartz and clay in triaxial porcelain composition. Indian Academy of Sciences, 35(5), 897-904.

11. Jamo, H.U. \& Maharaz, M.N. (2015), Influence of addition of rice husk ash on porcelain composition. Science World Journal, 10(1), 7-16

12. Kumar, A., Mohanta, K., Kumar, D. \& Parkash, O. (2012). Properties and industrial applications of rice husk: A review. International Journal of Emerging Technology and Advanced Engineering, 2(10), 88-90.

13. Kunchariyakun, K., Asavapisit, S. \& Sombatsompop, K. (2015). Properties of autoclaved Aerated concrete incorporating rice husk ash as partial replacement for fine aggregate. Cement and Concrete composites, 55, 11-16.

14. Lim, J.L.G., Raman, S.N., Lai, F.C., Zain, M.F.M. \& Hamid, R. (2018). Synthesis of nano cementitious additives from agricultural wastes for the production of sustainable concrete. Journal of Cleaner Production, 171, 1150-1160.

15. Medeiros, P.S.S., de Lira, H., de, L., Rodriguez, M.A., Menezes, R.R., Neves, G., de, A., \& Santana, L.N. (2019). Incorporation of quartzite waste in mixtures used to prepare sanitary ware. Journal of Materials Research and Technology, 8(2), $2148-2156$.

16. Oluseyi, A.K., Atul, M., \& Das, S.K. (2013). Effect of substitution of soda-lime scrap glass for K-feldspar in triaxial porcelain ceramic mix. INTERCERAM, 62(4), 299-302.

17. Prasad, C.S., Maiti, K.N., \& Venugopal, R. (2001). Effect of rice husk ash in whiteware compositions. Ceramic International, 27, 629-635.

18. Prasad, C.S., Maiti, K.N. \& Venugopal, R. (2002) Effect of silica fume addition on the properties of whiteware compositions. Ceramic International, 28(1), 9-15.

19. Rodriguez, E.A., Niño, C.J., Contreras, J.E., Vázquez-Rodríguez, F.J., López-Perales, J.A., Aguilar-Martínez, J.A., ... LaraBanda, M. (2019). Influence of incorporation of fired porcelain scrap as partial replacement of quartz on properties of an electrical porcelain. Journal of Cleaner Production, DOI: 10.1016/j.jclepro.2019.05.403

20. Sánchez, E., Ibáñez, M.J., García-Ten, J., Quereda, M.F., Hutchings, I.M., \& Xu, Y.M. (2006). Porcelain tile microstructure: Implications for polished tile properties. Journal of European Ceramic Society, 26, 2533-2540.

21. Sedghi, A., Hamidnezhad, N., \& Noori N.R. (2012) The effect of fluxes on alumina silicate porcelain insulator properties and structures. Proc. Inter. Conf. on Ecological, Environmental and Biological Sciences (Dubai) 7-8 January 2012, 343-345

22. Serra, M.F, Conconi, M.S, Gauna, M.R, Suarez, G, Aglietti, E.F \& Rendtorff, N.M. (2016). Mullite ( $\left(3 \mathrm{Al}_{2} \mathrm{O}_{3} .2 \mathrm{SiO}_{2}\right)$ ceramics obtained by reaction sintering of rice husk ash and alumina, phase evolution, sintering and microstructure. Journal of Asian Ceramic Societies, 4, 61-67.

23. Tucci, A., Esposito, L., Rastelli, E., Palmonari, C., \& Rambaldi, E. (2004). Use of soda-lime scrap-glass as a fluxing agent in a porcelain stoneware tile mix. J. Eur. Ceram. Soc., 24, 83-92. 